\section{'Argaman': A New, Highly Colored, Productive, vinifera Wine Cultivar}

\author{
P. Spiegel-Roy \\ Department of Fruit Tree Breeding and Genetics, The Volcani Center, Bet- \\ Dagan 50250, Israel
}

S. Cohen

The Israel Wine Institute, Rehovot 76120, Israel

\author{
I. Baron and R. Assaf \\ Department of Fruit Tree Breeding and Genetics, The Volcani Center, Bet- \\ Dagan 50250, Israel
}

\section{S. Ben-A'haron}

The Israel Wine Institute, Rehovot 76120, Israel

\section{M.J. Striem}

Department of Fruit Tree Breeding and Genetics, The Volcani Center, BetDagan 50250, Israel

Additional index words. Vitis, wine grape breeding

'Argaman' (the Hebrew word for "deep purple") is a new, highly colored, productive, vinifera wine cultivar (Fig. 1). Vines of 'Argaman' are vigorous, high yielding, and less sensitive than 'Carignan' to powdery mildew (Uncinula necator Burr.). 'Argaman' ripens 2 to 3 weeks before 'Carignan' with medium-sized, moderately compact clusters. 'Argaman' varietal wine is deeply colored with satisfactory to average acidity and tannins.

\section{Origin}

'Argaman' resulted from the cross 'Souzao' x 'Carignan' made in 1972. It was selected at Bet-Dagan and subsequently planted in 1984 as selection no. 401 at several test plots. This is the second release of a wine grape from the Agricultural Research Organization, The Volcani Center (after 'Roy' released in 1988; Israel Plant Patent No. 656/84).

'Souzao' is one of the better varieties of the port-producing regions of Portugal. It is vigorous and productive, and its wines are deeply colored with good acidity (Winkler et al., 1974). It can produce good-quality wines from warm sites and is tolerant to fungal diseases (Perold, 1927); however, 'Souzao' was unproductive at local sites. 'Carignan' is of Spanish origin and is one of the important wine varieties. It is very productive, thus useful for making bulk red table wines. However, 'Carignan' wines are of medium acidity and color and

\footnotetext{
Received for publication 13 Mar. 1996. Accepted for publication 13 July 1996 . We thank the growers who maintained test plots and supplied fruit samples for laboratory and wine analysis. We also wish to acknowledge the viticulture field advisors for help in supervising the test plots. The cost of publishing this paper was defrayed in part by the payment of page charges. Under postal regulations, this paper therefore must be hereby marked advertisement solely to indicate this fact.
}

with little varietal character (Winkler et al., 1974).

\section{Description}

Grafted vines of 'Argaman' (on Richter 110 and Ruggeri 140R rootstocks) are vigorous and productive with annual spur pruning. In three test plots, yields of 21 to $39 \mathrm{t}^{\text {ha }}{ }^{-1}$ have been obtained. This yield compares favorably with the mean yields of 'Carignan' at the same locations and with the same training systems (Table 1). Leaves resemble those of 'Carignan' as described by Galet (1976), are dark green, and have five distinct lobes. Compared to 'Carignan', the two lower sinuses are shorter and the two upper sinuses are broader. The petiolar sinus is medium-wide, U-shaped with large teeth, and asymmetrical. Foliage and fruit of 'Argaman' are apparently less sensitive to powdery mildew than 'Carignan', as determined by visual observation.

Flowers are perfect and self-fertile. Fruit clusters are medium-sized (280 to $300 \mathrm{~g}$ ), moderately compact, and cylindrical in shape (Fig. 1). 'Argaman' ripens about midseason (mid-August to early September), $\approx 1$ to 3 weeks before 'Carignan'. Berries are mediumsized (1.48 g), round, and range from blue to black, covered with a white waxy bloom.

Each year for five seasons (1988-92), wine samples from three test plots were made by the

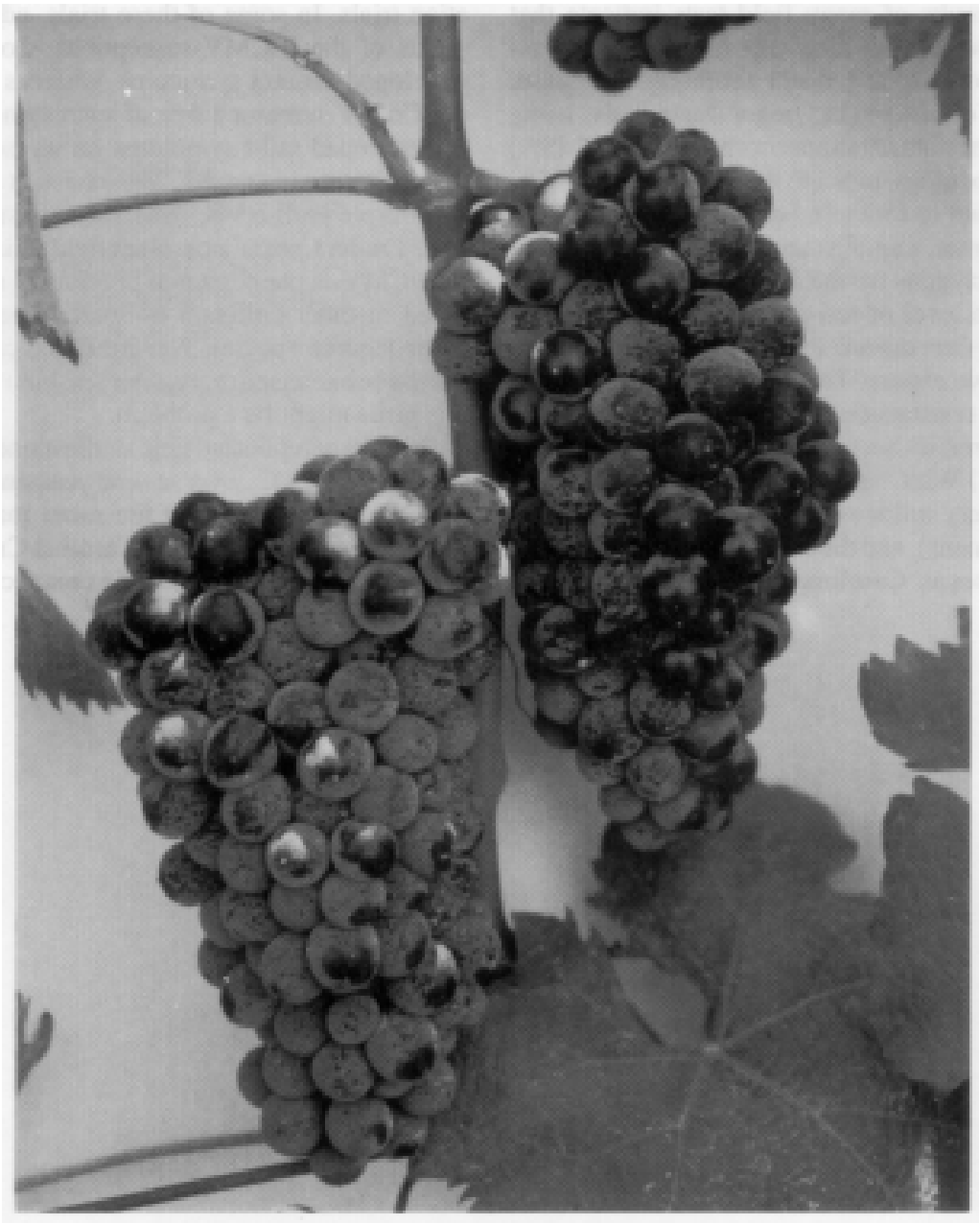

Fig. 1. Fruit clusters of 'Argaman' grape. 


\begin{tabular}{|c|c|c|c|c|c|c|c|c|c|c|c|c|}
\hline \multirow[b]{5}{*}{ Characteristic } & \multicolumn{12}{|c|}{ Date harvested } \\
\hline & \multicolumn{2}{|c|}{1988} & \multicolumn{2}{|c|}{1989} & \multicolumn{2}{|c|}{1990} & \multicolumn{2}{|c|}{1991} & \multicolumn{2}{|c|}{1992} & \multirow[b]{2}{*}{27 Aug. } & \multirow[b]{2}{*}{14 Sept. } \\
\hline & 28 Aug. & 5 Sept. & 24 Aug. & 1 Sept. & 27 Aug. & 14 Sept. & 21 Aug. & 28 Aug. & 25 Aug. & 19 Sept. & & \\
\hline & & & \multicolumn{6}{|c|}{ Cultivar } & & & \multicolumn{2}{|c|}{ Mean (SD) } \\
\hline & Argaman & Carignan & Argaman & Carignan & Argaman & Carignan & Argaman & Carignan & Argaman & Carignan & Argaman & Carignan \\
\hline$\overline{\text { Yield }\left(\mathrm{t} \cdot \mathrm{ha}^{-1}\right)}$ & 34.5 & 32.5 & 28.7 & 31.7 & 33.7 & 36.7 & 21.2 & 23.0 & 23.0 & 29.0 & $28.2(6.0)$ & $30.4(5.0)$ \\
\hline Alcohol (\%) & 10.8 & 11.0 & 11.3 & 10.6 & 10.9 & 10.0 & 10.7 & 10.7 & 11.3 & 11.2 & $11.0(0.28)$ & $10.7(0.45)$ \\
\hline \multicolumn{13}{|l|}{ Titratable acidity ${ }^{\mathrm{z}}$} \\
\hline$\left(g \cdot \mathrm{L}^{-1}\right)$ & 5.5 & 5.1 & 4.7 & 4.3 & 4.8 & 4.0 & 5.3 & 5.4 & 5.9 & 4.5 & $5.24(0.49)$ & $4.66(0.57)$ \\
\hline $\mathrm{pH}^{2}$ & 3.8 & 3.9 & 3.8 & 3.9 & 3.6 & 3.7 & 3.8 & 3.9 & 3.7 & 3.7 & $3.74(0.09)$ & $3.82(0.11)$ \\
\hline Color (OD $520 \mathrm{~nm}$ ) & 0.41 & 0.10 & 0.44 & 0.10 & 0.36 & 0.07 & 0.38 & 0.18 & 0.50 & 0.13 & $0.42(0.05)$ & $0.12(0.04)$ \\
\hline Potassium $\left(\mathrm{mg} \cdot \mathrm{L}^{-1}\right)$ & 1577 & 1690 & 1200 & 1467 & 907 & 950 & 1008 & 1437 & 1388 & 1532 & $1216(273)$ & $1415(278)$ \\
\hline \multicolumn{13}{|l|}{ Wine rating } \\
\hline$(\text { scale } 0 \text { to } 20)^{y}$ & 12.35 & 7.70 & 12.33 & 7.43 & 11.00 & 6.40 & 12.35 & 6.93 & 11.52 & 6.80 & $11.91(0.62)$ & $7.05(0.50)$ \\
\hline
\end{tabular}

${ }^{2}$ Postfermentation.

${ }^{y}$ Quality rating composed of: visual evaluation contributing $12 \%$; smell $24 \%$; flavor (mouth feel and aroma) contributing $40 \%$; and overall balance $24 \%$, of the total score.

Israeli Wine Institute. Wine tastings by a professional panel were blind and compared 'Argaman' and 'Carignan' from the same vineyards. The wine quality rating (on a scale of 0 to 20 , with 20 being the highest achievable score) was composed of visual evaluation, smell, flavor, and general aroma. 'Argaman' wines received favorable ratings, much higher than those of 'Carignan', in all 5 years (Table 1). 'Argaman' varietal wine is deeply colored with satisfactory to average acidity and tannins, of good body and balance.
'Argaman' has performed well in the first pilot plantings on the midcoastal plains, west to the Jerusalem hills, and was further planted in commercial vineyards, mainly as a substitute for 'Carignan'.

\section{Availability}

'Argaman' was registered for breeders' rights as plant patent no. 950 in Israel in 1992. Cuttings, upon agreement, are available from the Dept. for Fruit Tree Breeding and Genet- ics, The Agricultural Research Organization, The Volcani Center, Bet-Dagan 50250, Israel.

\section{Literature Cited}

Galet, P. 1976. Précis D'Ampelographie pratique. Imprimerie Paul Dehan, Montpellier.

Perold, A.I. 1927. A treatise on viticulture. Macmillan, London.

Winkler, A.J., J.A. Cook, W.M. Kliewer, and L.A. Lider . 1974. General viticulture. Univ. of California Press, Berkeley. 